\title{
Liposome-mediated RNA transfection should be used with caution
}

\author{
CARINE BARREAU, ${ }^{1,3}$ STÉPHANIE DUTERTRE, ${ }^{2}$ LUC PAILLARD, $^{1}$ and H. BEVERLEY OSBORNE ${ }^{1}$ \\ ${ }^{1}$ CNRS/Université de Rennes 1, UMR 6061 Génétique et Développement, IFR 140 Génétique Fonctionnelle, Agronomie et Santé, \\ Faculté de Médecine, 35043 Rennes cedex, France \\ ${ }^{2}$ IFR 140 Génétique Fonctionnelle, Agronomie et Santé, Plateforme de Microscopie Fluorescente, CNRS UMR 6061 Génétique et Développement, \\ Faculté de Médecine, 35043 Rennes cedex, France
}

\begin{abstract}
Liposome-mediated RNA transfection appears to present a number of advantages for studying the metabolism of reporter mRNAs in mammalian cells. This method is also widely used to transfect siRNAs. Here we describe results indicating that reporter mRNAs introduced into HeLa cells by liposomes do not present the expected behaviors. Namely, the stability of reporter mRNAs was independent of the presence or absence of an AUUUA instability element, a poly(A) tail, or even a 5' methylated cap. Confocal microscopy showed that fluorescent RNAs introduced by liposome-mediated transfection were present in discrete particles. These observations imply that a number of control experiments are required when using liposome to mediated RNA transfection, and the possible consequences are discussed.
\end{abstract}

Keywords: lipofection; AU-rich element; EDEN; mRNA degradation; localization

\section{INTRODUCTION}

A variety of methods can be used to introduce recombinant genes or gene products into cells. Although plasmid transfection is probably the most common approach, RNA transfection is increasingly being used. Microinjection has been successfully used for many decades to introduce various molecules into embryos of many species. Microinjection of nucleic acids or proteins into cultured cells is also possible with the aid of more specialized equipment. Many other protocols for the transfection of cultured cells with plasmids and RNAs have been developed, of which lipofection (liposome-mediated transfection) is widely used. Lipofection has the advantage that no specialized equipment is required, and as several companies have developed kits, experimental reproducibility can be good. Notably, lipofection is widely used for the transfection of si- and miRNAs. RNA transfection is also potentially interesting for the study of mechanisms controlling mRNA metabolism.

${ }^{3}$ Present address: Department of Zoology, University of Oxford, Oxford, OX1 3PS, United Kingdom.

Reprint requests to: H.B. Osborne, UMR 6061 Génétique et Développement, IFR 140 Génétique Fonctionnelle, Agronomie et Santé, Faculté de Médecine, 2 avenue du Pr. Léon Bernard, CNRS/Université de Rennes 1, 35043 Rennes cedex, France; e-mail: Beverley.osborne@univ-rennes1.fr; fax: 33-223-23-4478.

Article published online ahead of print. Article and publication date are at http://www.rnajournal.org/cgi/doi/10.1261/rna.191706.
Ongoing research in our laboratory is concerned with the identification of cis-acting elements and trans-acting factors that regulate mRNA stability and translation in Xenopus embryos. To pursue this research using cultured mammalian cells, we initiated a program using HeLa and NIH-3T3 cells transfected either with mRNAs or plasmids. When plasmids encoding reputed stable or unstable mRNAs were transfected, the resulting mRNAs presented the expected stabilities (data not shown). In contrast, when the reporter mRNAs were directly transfected using a lipofection protocol, we rapidly realized that even those reputed to be highly unstable in mammalian cells were not degraded. To clarify this enigma, a number of capped and polyadenylated reporter mRNAs were transfected into HeLa cells using liposomes. Several of these mRNAs contained AU-rich sequence elements (AREs) that cause rapid mRNA degradation in mammalian cells (Chen and Shyu 1995; Wilson and Brewer 1999), and we expected that these mRNAs would be unstable. This was the case of the mRNAs, GbORF-AUUUA (class II ARE), GbORF-junARE (class III ARE), and Cat-EDEN (class III ARE). Other mRNAs were expected to be more stable; these were the GbORF and Cat-EDENas (anti-sens EDEN) mRNAs. However, after transfection into HeLa cells, the persistence of the ARE-containing or non-ARE mRNAs was not significantly different (Fig. 1A). The half-lives of all these transfected mRNAs were situated between $5 \mathrm{~h}$ and $14 \mathrm{~h}$ and, 


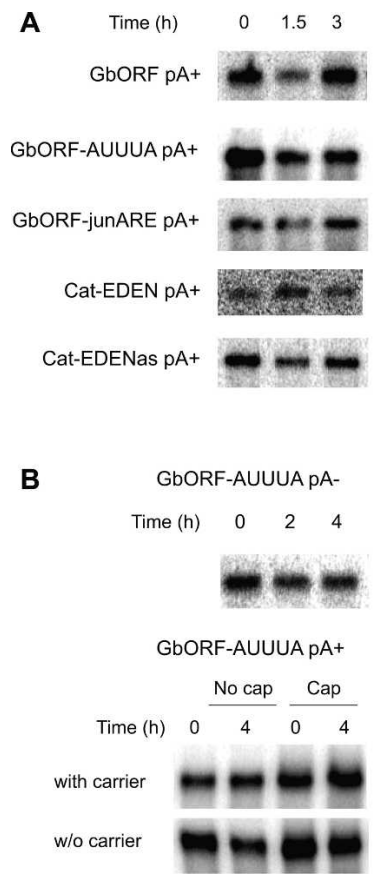

FIGURE 1. Aberrant stability of transfected RNAs. (A) The various capped and ${ }^{32} \mathrm{P}$-labeled mRNAs, indicated on the left, were transcribed in vitro from the appropriate plasmids linearized by restriction with EcoRV and using the mMessage mMachine (Ambion) kit with the T7 polymerase: GbORF $\mathrm{pA}^{+}$and pGbORF (Audic et al. 1997); GbORF-AUUUA pA ${ }^{+}$, pGbORF-AUUUA, GbORF-junARE $\mathrm{pA}^{+}$, and pGbORF-jun (Paillard et al. 2002); or the SP6 polymerase Cat-EDEN $\mathrm{pA}^{+}$, pCESA 14, Cat-EDENas $\mathrm{pA}^{+}$, and pCEASA 3 (Ezzeddine et al. 2002). The in vitro transcripts were purified and verified by PAGE before use. HeLa cells (12-well culture dish seeded at $10^{5}$ cells per well the day before use) were transfected using the DMRIE-C lipofectant (Invitrogen; $2 \mathrm{mg} / \mathrm{mL}$ ) according to the manufacture's instructions. Briefly, $400 \mu \mathrm{L}$ of opti-MEM supplemented with $10 \mu \mathrm{L}$ of lipofectant and 2-3 pmol of RNA were added to each well, and the cells were cultured at $37^{\circ} \mathrm{C} / 5 \% \mathrm{CO}_{2}$ for $2 \mathrm{~h}$. The lipofectant was then removed by washing with $\mathrm{PBS}$ and the culture continued at $37^{\circ} \mathrm{C} / 5 \% \mathrm{CO}_{2}$ after adding $1 \mathrm{~mL} /$ well of DMEM supplemented with $10 \%$ fetal calf serum. At the indicated times, the medium was removed and total RNA was extracted by the addition of $400 \mu \mathrm{L}$ of TriReagent (Medical Research Center Inc.) per well. The extracted RNAs were separated by electrophoresis on a $2 \%$ agarose MOPS/formaldehyde gel and transferred onto a Hybond $\mathrm{N}^{+}$membrane (Amersham), and the fixed membrane was exposed to a phosphoimager screen. The radioactive signals were revealed using a Storm phosphoimager and then quantified by the ImageQuant software. (B) Hela cells were transfected, as described in $A$, by GbORF-AUUUA mRNA devoid of a poly $(A)$ tail (GbORF-AUUUA $\mathrm{pA}^{-}$(upper panel) or either uncapped or capped (respectively, No cap and Cap; bottom panel). The poly $(A)^{-}$mRNA was synthesized using pGbORF-AUUUA restricted with BamHI. To synthesize uncapped mRNA, the cap analog was omitted from the transcription reaction. The radioactive capped and uncapped mRNAs (10 fmol) were either added alone to the lipofectant (w/o carrier) or supplemented with 2.5 pmol of nonradioactive GbORF or GbORF-AUUUA $\mathrm{pA}^{+}$as appropriate (with carrier). The transfected cells were cultured and the total RNA extracted and analyzed as described in $A$. $(C)$ HeLa cells were transfected, as described in $A$, by GbORF pA ${ }^{+}$and GbORFAUUUA $\mathrm{pA}^{+}$mRNAs as indicated. (Upper panel) After removal of the culture medium, the cells were washed with $1 \mathrm{~mL}$ of PBS and then detached from the dish with $100 \mu \mathrm{L}$ of TrypsinEDTA solution (Invitrogen). After an incubation for 2 min at $37^{\circ} \mathrm{C}, 900 \mu \mathrm{L}$ of DMEM supplemented with $10 \%$ fetal calf serum was added and the cells collected by centrifugation $(1500 \mathrm{~g}, 5 \mathrm{~min}$, room temperature). Total RNA was extracted from the cell pellet with $400 \mu \mathrm{L}$ of Tri-reagent (lane Cells). To determine the amount of ${ }^{32} \mathrm{P}$-labeled RNA remaining in wells after removal of the cells, $400 \mu \mathrm{L}$ of Tri-reagent and untransfected cells treated with trypsin (acting as carrier for RNA extraction) were added after removal of the transfected cells (lane Well). The total RNA extracted from the various samples was processed and the ${ }^{32} \mathrm{P}$-labeled RNA visualized as described in A. (Lower panel) After transfection the cells were cultured for the indicated times. The cells were then detached from the culture dish with trypsin, processed and analyzed as described for the upper panel. above all, varied between experiments (Fig. 1C, lower panel; data not shown). In an attempt to make a hyper-unstable mRNA, we synthesized a nonadenylated version of the GbORF-AUUUA mRNA, and this mRNA was transfected into HeLa cells using liposomes (Fig. 1B, upper panel). This mRNA was also very stable, showing only minimal degradation over a 4 -h incubation period. In addition to nonadenylated mRNAs, we also transfected the cells with a noncapped mRNA, which we expected would be rapidly degraded. However, both the capped and noncapped versions of GbORF-AUUUA mRNA were equally stable (Fig. 1B, lower panel, top row). In this last experiment, the radiolabeled mRNA had been mixed with an excess (250-fold) of carrier nonradioactive mRNA of the same species. To ensure that the amount of transfected mRNA was not too high, which may result in a saturation of the cellular machinery and hence cause the abnormal stability, the carrier mRNA was omitted from some of the samples (Fig. 1B, lower panel, bottom row). No difference in the stability of the capped or noncapped GbORF-AUUUA mRNA was observed.

We next reasoned that this apparent stability of all the transfected mRNAs may be due to a contamination in the cell extracts by extracellular (nonfused) liposomes. Initially, therefore, the cell layer was both extensively washed with PBS and incubated $\left(1 \mathrm{~h}, 37^{\circ} \mathrm{C}\right)$ with up to $200 \mu \mathrm{g} / \mathrm{mL}$ RNase A before extraction of the RNAs with Tri-reagent. This treatment only led to a small decrease in the radioactive RNAs extracted from the cells and did not reveal the expected degradation of the reporter mRNAs containing the AREs (data not shown). To evaluate a possible contamination from RNA-containing liposomes attached to the plastic surface of the culture dish, the cell layer was dissociated from the plastic support with trypsin and Tri-reagent added to both the cell pellet and the well of the cell culture dish after removal of the cells. The analysis of the radioactive RNA extracted from these samples (Fig. 1C, 
upper panel) showed that although transfected RNAs were extracted from the cells detached with trypsin (lane Cells), a very significant amount was also extracted from the well after removal of the cells (lane Well). Despite the removal of these contaminating RNAs, little degradation of the transfected mRNAs still was observed (Fig. $1 \mathrm{C}$, lower panel). In this experiment, which is representative of the variations in mRNA degradation observed, the GbORF-AUUUA mRNA containing a type II ARE is more stable $(\mathrm{t}=13.5 \mathrm{~h})$ than is the GbORF mRNA ( $\mathrm{t}=5.5 \mathrm{~h})$.

These various observations led us to conclude that the reporter mRNAs transfected into the cells by lipofection are probably in a cellular compartment that protects the bulk from the degradation machinery of the cell. To visualize the transfected mRNAs, HeLa cells were transfected with fluorescent-labeled (Cy3) RNAs and then fixed either immediately after removal of the lipofectant solution or $3 \mathrm{~h}$ later. After staining the cells with a fluorescent membrane marker (Alexa Fluor 488 labeled wheat germ agglutinin) and the nuclear stain DAPI, the cells were observed by confocal microscopy. The images obtained from the cells at $0 \mathrm{~h}$ and $3 \mathrm{~h}$ after transfection were not significantly different. The membrane marker clearly delimited the cells and also revealed a number of punctuate structures both inside and outside the cells (Fig. 2, left column). Surprisingly, the RNA-associated fluorescence was also concentrated in punctuate structures (Fig. 2, middle column), a small and variable number of which were associated with the plasma membrane. Superposition of the membrane and RNA fluorescence images (Fig. 2, right lane) showed that the vast majority of the RNAassociated fluorescence colocalized with the punctuate membrane structures.

Our interpretation of these data is that most of the transfected RNAs are confined in a cellular compartment that sequesters the molecules away from the cytoplasmic machineries responsible for mRNA degradation and probably translation. The sequestering of the majority of the transfected RNA molecules would explain the unexpected stability of mRNAs containing either type II and III AREs or devoid of either a poly(A) tail or a $5^{\prime}$ cap. However, some of the transfected RNAs must be released into the cytoplasm as the production of a fluorescent reporter protein, encoded by the transfected mRNA, was observed with the transfection protocol used here (data not shown). The proportion of transfected mRNA that is released into the cytoplasm, relative to the sequestered mRNA, is probably low and dependent on many parameters, which could explain the variability we observed in the half-lives of the reporter mRNAs. Furthermore, liposome-mediated transfection of mi- or si-RNAs can, respectively, inhibit the translation or cause the degradation of the targeted mRNA, again an observation that we have confirmed (data not shown).

The presence of the transfected mRNA in two cellular compartments could lead to an apparent, but probably artifactual, uncoupling of the functional (translation) and physical (stability) half-lives of the transfected mRNA. A lack of correlation between translational arrest and degradation has been clearly demonstrated in early embryos of several species (for review, see Vasudevan et al. 2006) and also when mRNAs are sequestered in stress granules 
(for review, see Kedersha and Anderson 2002). These are different situations from the one we describe here. Although a clear identification of the cellular compartment or structure containing the transfected RNAs can only be obtained by determining their colocalization with specific markers, we note that the sequestered transfected mRNAs appear to be associated with membranes, and to our knowledge, stress granules are not membrane-bound structures (see Gilks et al. 2004).

Recently, several publications have used lipofection of reporters to study the mechanisms by which miRNAs repress the translation of target mRNAs. The reporter mRNAs were either expressed from transfected plasmids (Pillai et al. 2005; Petersen et al. 2006) or directly transfected (Humphreys et al. 2005; Pillai et al. 2005). In the present context, it is interesting to note that although the mi-RNA mediated translational repression was not proportional to mRNA degradation, the repressed reporter mRNAs were more unstable when expressed from a plasmid (Pillai et al. 2005; Petersen et al. 2006) than when transfected directly (Humphreys et al. 2005). Furthermore, miRNAs did not affect the IRES-dependent translation of transfected RNAs (Pillai et al. 2005) but did repress this translation when the mRNA was expressed from a plamid (Petersen et al. 2006). Whether this was due to the fate of the transfected mRNA or the nuclear history of the mRNA expressed from the plasmid is not clear. The measurement of mRNA stability was not the major objective of these studies, and it is not clear in what way the sequestering of a large part of the transfected mRNAs could affect the many observations reported in these publications. Despite these considerations and in light of the results we describe here, we believe that these and any similar results should be re-evaluated.

In conclusion, our observations indicate that using lipofection to transfect mammalian cells with RNA is highly inefficient with respect to the proportion of the cellassociated molecules that are really functional. In addition, the large proportion of "unused" RNA molecules could become toxic for the cell or trigger a response such as stress that could change cell metabolism. Based on these observations, several recommendations can be made. First, for RNAs, methods such as electroporation or microinjection should be preferred to lipofection. Second, if lipofection is the only method available to an experimenter to achieve RNA transfection, then the transfected RNA should be spiked with a fluorescent RNA to verify the intracellular destiny of the RNA or, at least, a positive control of degradation such as an RNA without a cap, should be added. Last, the use of lipofection protocols with siRNAs to achieve RNA interference may need to be re-evaluated. This could be particularly relevant to cases where it is suspected that the "unused" transfected RNAs may interfere with the observed effects. Accordingly, in certain cases, the use of plasmids or viruses encoding shRNA may be preferable to the lipofection of siRNAs.

\section{ACKNOWLEDGMENTS}

This work was supported by grants from the Region Bretagne PRIR- Cytomod, ARC (Contract no. 4791), and Ministère Délégué à la Recherche (ACI BCMS314). During part of this work, C.B. received post-doctoral fellowships from the CNRS and Rennes Métropole.

Received June 14, 2006; accepted July 17, 2006.

\section{REFERENCES}

Audic, Y., Omilli, F., and Osborne, H.B. 1997. Postfertilization deadenylation of mRNAs in Xenopus laevis embryos is sufficient to cause their degradation at the blastula stage. Mol. Cell. Biol. 17: 209-218.

Chen, C.-Y.A. and Shyu, A.-B. 1995. AU-rich elements: Characterization and importance in mRNA degradation. Trends Biochem. Sci. 20: $465-470$.

Ezzeddine, N., Paillard, L., Capri, M., Maniey, D., Bassez, T., AïtAhmed, O., and Osborne, B. 2002. EDEN dependent translational repression of maternal mRNAs is conserved between Xenopus and Drosophila. Proc. Natl. Acad. Sci. 99: 257-262.

Gilks, N., Kedersha, N., Ayodele, M., Shen, L., Stoecklin, G., Dember, L.M., and Anderson, P. 2004. Stress granule assembly is mediated by prion-like aggregation of TIA-1. Mol. Biol. Cell 15: 5383-5398.

Humphreys, D.T., Westman, B.J., Martin, D.I., and Preiss, T. 2005. MicroRNAs control translation initiation by inhibiting eukaryotic initiation factor 4E/cap and poly(A) tail function. Proc. Natl. Acad. Sci. 102: 16961-16966.

Kedersha, N. and Anderson, P. 2002. Stress granules: Sites of mRNA triage that regulate mRNA stability and translatability. Biochem. Soc. Trans. 30: 963-969.

Paillard, L., Legagneux, V., Maniey, D., and Osborne, H.B. 2002. c-Jun ARE targets mRNA deadenylation by an EDEN-BP (embryo deadenylation element-binding protein)-dependent pathway. J. Biol. Chem. 277: 3232-3235.

Petersen, C.P., Bordeleau, M.-E., Pelletier, J., and Sharp, P.A. 2006. Short RNAs repress translation after initiation in mammalian cells. Mol. Cell 21: 533-542.

Pillai, R.S., Bhattacharyya, S.N., Artus, C.G., Zoller, T., Cougot, N., Basyuk, E., Bertrand, E., and Filipowicz, W. 2005. Inhibition of translation initiation by Let-7 microRNA in human cells. Science 309: 1573-1576.

Vasudevan, S., Seli, E., and Steitz, J.A. 2006. Metazoan oocyte and early embryo development program: A progression through translation regulatory cascades. Genes \& Dev. 20: 138-146.

Wilson, G.M. and Brewer, G. 1999. The search for trans-acting factors controlling messenger RNA decay. Prog. Nucleic Acid Res. Mol. Biol. 62: 257-291. 

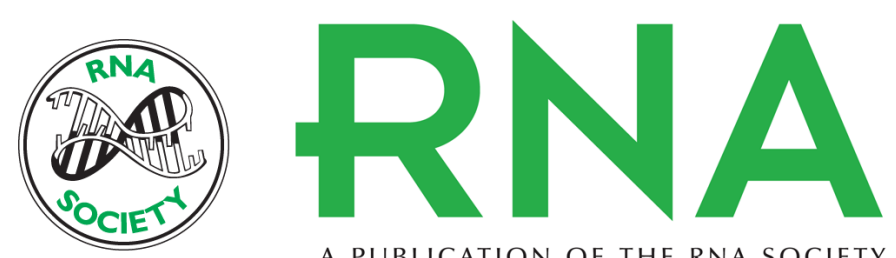

A PUBLICATION OF THE RNA SOCIETY

\section{Liposome-mediated RNA transfection should be used with caution}

Carine Barreau, Stéphanie Dutertre, Luc Paillard, et al.

RNA 2006 12: 1790-1793

References This article cites 11 articles, 7 of which can be accessed free at:

http://rnajournal.cshlp.org/content/12/10/1790.full.html\#ref-list-1

License

Email Alerting Receive free email alerts when new articles cite this article - sign up in the box at the Service top right corner of the article or click here.

To subscribe to RNA go to:

http://rnajournal.cshlp.org/subscriptions 